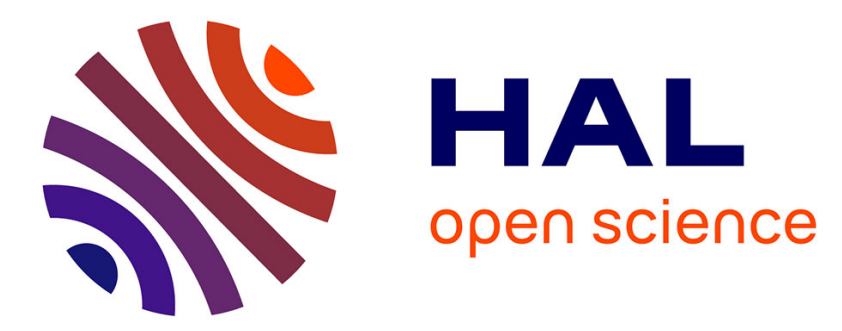

\title{
Ferroelectric PbTiO3 films grown by pulsed liquid injection metalorganic chemical vapour deposition
}

Ausrine Bartasyte, Adulfas Abrutis, Carmen Jiménez, François Weiss, Odette Chaix-Pluchery, Z. Saltyte

\section{- To cite this version:}

Ausrine Bartasyte, Adulfas Abrutis, Carmen Jiménez, François Weiss, Odette Chaix-Pluchery, et al.. Ferroelectric PbTiO3 films grown by pulsed liquid injection metalorganic chemical vapour deposition. Ferroelectrics, 2006, 353, pp.104. hal-00261123

HAL Id: hal-00261123

https://hal.science/hal-00261123

Submitted on 6 Mar 2008

HAL is a multi-disciplinary open access archive for the deposit and dissemination of scientific research documents, whether they are published or not. The documents may come from teaching and research institutions in France or abroad, or from public or private research centers.
L'archive ouverte pluridisciplinaire HAL, est destinée au dépôt et à la diffusion de documents scientifiques de niveau recherche, publiés ou non, émanant des établissements d'enseignement et de recherche français ou étrangers, des laboratoires publics ou privés. 


\title{
Ferroelectric $\mathrm{PbTiO}_{3}$ films grown by pulsed liquid injection
}

\section{metalorganic chemical vapour deposition}

\author{
A. Bartasyte ${ }^{* 1,2}$, A. Abrutis ${ }^{1}$, C. Jimenez ${ }^{2}$, F. Weiss ${ }^{2}$, O. Chaix-Pluchery ${ }^{2}$, Z. Saltyte ${ }^{1}$ \\ ${ }^{1}$ Vilnius University, Dept. of General and Inorganic Chemistry, Naugarduko 24, LT-03225 \\ Vilnius, Lithuania \\ ${ }^{2}$ Laboratoire des Matériaux et du Génie Physique (CNRS-INP Grenoble), Minatec, 3 parvis \\ Louis Néel, BP 257, 38016 Grenoble Cedex 1, France
}

\begin{abstract}
The influence of various deposition conditions (deposition temperature, partial oxygen pressure and solution composition) to the growth of ferroelectric $\mathrm{PbTiO}_{3}$ (PTO) films by pulsed liquid injection metalorganic chemical vapour deposition (MOCVD) was examined. Films were grown on $\mathrm{LaAlO}_{3}(001), \mathrm{SrTiO}_{3}(001)$ and sapphire (R-plane) substrates. $\mathrm{Pb}$ (thd) $)_{2}$ and $\operatorname{Ti}\left(\mathrm{O}^{\mathrm{i}} \mathrm{Pr}\right)_{2}(\text { thd })_{2}$ (thd = 2,2,6,6-tetramethyl-3,5-heptanedionate) dissolved in toluene were used as precursors. The evolution of film composition, surface morphology and microstructure with deposition conditions was studied. The film microstructure was characterized by X-ray diffraction (XRD) in Bragg-Brentano and Schulz geometries and by Raman spectroscopy. Epitaxial films on perovskite substrates consisted of dominant c-axis and minor a-axis textured zones ( $c$-domains and $a$-domains). The amount of $a$-domains in films depended mainly on deposition temperature. The twinning in $a$ - and $c$-domains was observed and twinning (tilt) angles depended on deposition conditions and substrate. Fully twinned or partially twinned films were obtained in varying deposition conditions. The best quality epitaxial films were obtained on $\mathrm{SrTiO}_{3}$ and $\mathrm{LaAlO}_{3}$ at $650{ }^{\circ} \mathrm{C}$. Films on sapphire were mainly polycrystalline.
\end{abstract}

Keywords: liquid injection $\mathrm{MOCVD}, \mathrm{PbTiO}_{3}$ films, twinning.

\footnotetext{
*Electronic Address: Ausrine.Bartasyte@gmail.fr
} 


\section{Introduction}

Lead-based ferroelectric oxides, such as $\mathrm{PbTiO}_{3}(\mathrm{PTO}), \mathrm{PbTi}_{1-\mathrm{x}} \mathrm{Zr}_{\mathrm{x}} \mathrm{O}_{3}$ (PZT) and etc., have been widely investigated as materials for applications in microelectronics [1], piezoelectric devices [2] and infrared sensors [3]. $\mathrm{PbTiO}_{3}$ thin films attracted much attention due to high Curie temperature, low dielectric constant and high pyroelectric coefficient. Ferroelectric properties originate from the structural anisotropy, so high quality epitaxial films are required to take full advantage of the material properties and for applications in devices. Epitaxial PTO films have been grown by metalorganic chemical vapour deposition (MOCVD) [4-8], pulsed laser deposition (PLD) [9,10] and rf-magnetron sputtering [11]. Among various preparation methods, MOCVD has been recognized as the most promising technique due to the possibility to grow films on large area with high growth rate and good conformal step coverage.

In the literature, mainly liquid $\mathrm{PbEt}_{4}$ and $\mathrm{Ti}\left(\mathrm{O}^{\mathrm{i}} \mathrm{Pr}\right)_{4}$ compounds were used as precursors for MOCVD growth of PTO films by bubbling of carrier gas through containers of liquid precursors [5, 6, 12-16]. However, some other pairs of $\mathrm{Pb}$ and Ti precursors have been also studied: $\mathrm{Pb}(\text { thd })_{2}$ (thd $=$ 2,2,6,6-tetramethyl-3,5-heptanedionate) and $\operatorname{Ti}\left(\mathrm{O}^{\mathrm{i}} \mathrm{Pr}\right)_{4}$ [17-20], $\left(\mathrm{C}_{2} \mathrm{H}_{5}\right)_{3} \mathrm{PbOCH}_{2} \mathrm{C}\left(\mathrm{CH}_{3}\right)_{3}$ and $\mathrm{Ti}\left(\mathrm{O}^{\mathrm{i}} \mathrm{Pr}\right)_{4}$ [21], $\mathrm{Pb}(\mathrm{OAc})_{2}$ and $\mathrm{Ti}(\mathrm{OnBu})_{4}$ [22], $\mathrm{PbEt}_{4}$ and Ti-npropoxyde [23] or $\mathrm{PbEt}_{4}$ and $\mathrm{TiCl}_{4}$ [24]. Only several works [25, 26] can be found on the use of solid $\mathrm{Pb}(\text { thd })_{2}$ and $\mathrm{Ti}\left(\mathrm{O}^{\mathrm{i}} \mathrm{Pr}\right)_{2}$ (thd $)_{2}$ or $\mathrm{TiO}(\text { thd })_{2}$ precursors for PTO depositions. In these works, the vapour phase was generated by flash evaporation of a mixture of solid $\mathrm{Pb}$ and $\mathrm{Ti}$ precursors supplied into an evaporator. Solid metalorganic precursors are often preferred because they are non-toxic and more stable at room temperature as compared with liquid and extremely toxic tetraethyl lead precursor. In the last years, single source liquid injection MOCVD techniques have been more and more used for the growth of multi-component oxide layers. Moreover, these techniques allow an easier control of the composition of multi-component films and a better reproducibility of the process than conventional CVD.

In the present paper, we report on the role of oxygen partial pressure, deposition temperature and solution composition in the growth of $\mathrm{PbTiO}_{3}$ films by pulsed liquid injection MOCVD using $\mathrm{Pb}$ (thd $)_{2}$ and $\mathrm{Ti}\left(\mathrm{O}^{\mathrm{i}} \mathrm{Pr}\right)_{2}$ (thd $)_{2}$ precursors dissolved in an organic solvent. The influence of such parameters on films microstucture, composition and morphology was studied.

\section{Experimental details}


Depositions were carried out by pulsed liquid injection MOCVD technique [27-29] in a vertical hot wall reactor. Microdoses (a few microliters) of an organic solution containing a mixture of metalorganic precursors were repeatedly injected into a hot evaporator using a special computer controlled injector. The vapour mixture (precursor + solvent) formed after flash evaporation of micro-doses was transported by an $\mathrm{Ar}+\mathrm{O}_{2}$ gas flow into a reaction chamber to a hot substrate. The main advantages of this technique are an easy control of precursor feeding rate, vapour and film composition. Moreover, precise and reproducible pulsed microdosing of precursor solution ensures growth like "digital", and consequently a simple control of film thickness by pulse number.

Main deposition conditions are summarised in Table 1.

$\mathrm{Pb}(\text { thd })_{2}$ and $\mathrm{Ti}(\text { thd })_{2}(\mathrm{OiPr})_{2}$ precursors were synthesized and purified in our laboratory at Vilnius university. It is worth noting that the quality of precursors, especially of $\mathrm{Pb}(\mathrm{thd})_{2}$, is crucial for obtaining good quality PTO films. For example, we tried to test some commercial $\mathrm{Pb}(\text { thd })_{2}$ precursors and we always had problems to prepare clear solutions without turbidity.

The morphology of the film surface was examined by using scanning electron microscopy (SEM) (Philips XL30) and atomic force microscopy (AFM) (Digital instruments Multimode Scanning Probe Microscope, tapping mode). Films on Si were etched with concentrated HF in order to form a step for thickness determination by profilometry. The film thickness on other substrates was measured from the film cross-section images obtained by SEM. Energy dispersive X-ray spectroscopy (EDS) or wavelength dispersive X-ray spectroscopy (WDS) analysis was used for the evaluation of the film composition. Crystallization, phase purity, inplane and out-of plane orientation of the films were studied by X-ray diffraction (XRD) in Bragg-Brentano and Schulz geometries using a SIEMENS D5000 diffractometer with monochromatic $\mathrm{CuK}_{\alpha 1}$ radiation $(\lambda=0.15406 \mathrm{~nm})$. The percentage of a-axis oriented domains $(\mathrm{A}, \%)$ in the films was calculated by peak integration of the (102) reflection in $\varphi$-scans corresponding to the different domains:

$$
A=\frac{2 *\left(I(102)_{\chi=58}+I(102)_{\chi=62}\right)}{2 *\left(I(102)_{\chi=58}+I(102)_{\chi=62}\right)+I(102)_{\chi=27}} * 100 \%,
$$

where $\mathrm{I}$ is the peak integral intensity in $\varphi$-scans measured at different $\chi$ angles, corresponding to a-axis $\left(\chi=58^{\circ}\right.$ or $\left.62^{\circ}\right)$ and c-axis $\left(\chi=27^{\circ}\right)$ oriented crystallites (i.e. $a$ - and $c$-domains). $\chi$ angles were determined from $\chi$-scans of (102) reflection.

Raman spectra were collected using a Jobin-Yvon/Horiba Labram multichannel 
spectrometer equipped with a liquid $\mathrm{N}_{2}$ cooled CCD detector. Experiments were conducted in the micro-Raman mode at room temperature, in a backscattering geometry. The $514.5 \mathrm{~nm}$ line of an $\mathrm{Ar}^{+}$laser was focused to a spot size smaller than $1 \mu \mathrm{m}$. The recorded spectra were calibrated using Si spectra at room temperature. The integration times were adjusted in order to have a high signal-to-noise ratio.

\section{Results and discussion}

\subsection{Effects of oxygen partial pressure}

In order to test the oxygen effect on $\mathrm{Pb}$ content of the film, PTO films were grown at $650^{\circ} \mathrm{C}$ at four different oxygen partial pressures. Composition analysis showed that the maximum $\mathrm{Pb}$ content in films was obtained using $37.5 \%$ oxygen in the gas flow (Fig. 1a). The maximum growth rate $(1.03 \mu \mathrm{m} / \mathrm{h})$ of the films was obtained also at $37.5 \% \mathrm{O}_{2}$. L.S. Hong et al. [13] established that an increase of $\mathrm{O}_{2}$ concentration in gas promotes the $\mathrm{PbO}$ formation resulting in higher growth rate. However, too high oxygen concentration resulted in $\mathrm{Pb}$ deficient films, that was explained by stabilisation of high valency $\mathrm{Pb}_{3} \mathrm{O}_{4}$ and $\mathrm{PbO}_{2}$ at higher $\mathrm{O}_{2}$ partial pressures [13]. The optimum percentage of oxygen in the gas flow is highly dependent on the precursor type and its thermal stability. For example, in case of $\mathrm{Pb}\left(\mathrm{C}_{2} \mathrm{H}_{5}\right)_{4}$ only $1 \%$ of $\mathrm{O}_{2}$ in gas flow was sufficient [13], while in our case it was necessary to use much more oxygen. In further depositions, we used $37.5 \%$ oxygen in the gas flow.

$\mathrm{Pb}$ may be lost from PTO film during post-deposition treatment at higher temperatures or during the slow cooling after deposition at high deposition temperature. To get more information about the lead loss at high temperatures, several series of rapid thermal annealing (RTA) for $10 \mathrm{~min}$ at different temperatures and oxygen partial pressures were carried out. The composition of annealed films was analyzed by WDS and results are given in Fig. 1b. The films started to lose $\mathrm{Pb}$ at $700{ }^{\circ} \mathrm{C}$ and the $\mathrm{Pb}$ loss rate rapidly increased with further increase of annealing temperature. The lead content did not change after annealing at lower temperatures. One can see in Fig. $1 \mathrm{~b}$ that the $\mathrm{Pb}$ desorption rate can be reduced by increasing oxygen partial pressure. It means that high oxygen pressure during cooling stabilizes the $\mathrm{PbTiO}_{3}$ phase in our films. In order to minimize the $\mathrm{Pb}$ loss, we used 0.4 atm $\mathrm{O}_{2}$ pressure during film cooling from high deposition temperature.

\subsection{Composition and morphology}


Series of films were deposited at different temperatures in varying the solution composition. The composition of films deposited on $\mathrm{LaAlO}_{3}$ (LAO) was analyzed by WDS. Results are given in Fig. 2. It is evident that higher deposition temperatures require higher $\mathrm{Pb}$ precursor content in solution to achieve the right cationic proportion in the film. This may be related to higher lead oxide desorption at higher temperatures. At low $\mathrm{T}_{\text {dep }}=550{ }^{\circ} \mathrm{C}$, the $\mathrm{Pb}$ content in film gradually increases with the $\mathrm{Pb}$ content in solution. At higher deposition temperatures, the $\mathrm{Pb}$ fraction in the film increases until near stoichiometric value; it remains almost stable during further increase of the $\mathrm{Pb}$ content in solution. The minimum $\mathrm{Pb}$ content in solution necessary for achieving right $\mathrm{Pb}$ :Ti ratio in film may be named as "stoichiometric". Although films grown from solution with $\mathrm{Pb}$ precursor excess may have right cationic ratio, they consist not only of tetragonal $\mathrm{PbTiO}_{3}$ phase but also contain some additional phases $\left(\mathrm{PbTi}_{0.8} \mathrm{O}_{2.6}, \mathrm{PbO}\right)$.

The morphology of PTO films is very dependent on the solution composition especially for epitaxial films on $\mathrm{LAO}$ and $\mathrm{SrTiO}_{3}$ (STO) substrates (Fig. 3). Films grown from Pb deficient or "stoichiometric" solutions on both substrates have similar surface morphologies. On the other hand, the morphology of PTO films on sapphire is fully determined by island growth at all deposition temperatures resulting in rather rough film surface $(\mathrm{Ra}=3-7 \mathrm{~nm})$.

Layers grown from solution with $\mathrm{Pb}$ deficit are made up of two zones, which become better separated in films deposited at higher temperatures (Fig. 3). XRD showed that these films consisted of tetragonal PTO and pyrochlore phases (Fig. 4). One zone is very smooth and the second one is formed from small crystallites. As these different zones are clearly visible by optic microscope, Raman spectra in each zone have been measured (Fig. 5). One can see that the smooth zone consists only of tetragonal PTO phase. The other zone presents a phase with lower symmetry than tetragonal PTO - it can be considered as monoclinic pyrochlore phase. Such film morphology (called "rosette-shaped") was also observed by other authors [30-32] and was considered as perovskite islands in a pyrochlore matrix.

With the increase of $\mathrm{Pb}$ content in solution, smooth PTO zones become bigger and all the surface becomes smooth at $\mathrm{Pb} / \mathrm{Ti}=1$ in the film. The morphology of $\mathrm{PTO}$ films is defined by two factors: island growth and twinning (this aspect will be discussed in detail in the next section). Twinning results in a film morphology with perpendicular line shaped zones [33]. At higher temperatures, twinning becomes the leading factor for surface morphology of PTO films. For example, the morphology of films grown at $650 \mathrm{C}$ and higher temperature is mainly determined by twinning. Less twinned zones are observed in films grown at $600{ }^{\circ} \mathrm{C}$. The morphology of films deposited at $550{ }^{\circ} \mathrm{C}$ is completely determined by island growth resulting 
in a rather rough surface compared to the twinned layers. Thus, the roughness of the films grown from "stoichiometric" solutions decreases with the increase of deposition temperature (Fig. 6), and Ra reaches a very low value, $0.6 \mathrm{~nm}$ for films grown at $750{ }^{\circ} \mathrm{C}$.

PTO films grown on STO substrates from solutions with $\mathrm{Pb}$ excess consist of spherical grains forming the structure of lines (Fig. 3). Such structure becomes more ordered with increasing growth temperature and at $700 \mathrm{C}$ the lines are quasi parallel. In contrast, films on LAO substrates consist also of spherical grains but the line shaped structure is not observed.

\subsection{Microstructure}

PTO films on sapphire are polycrystalline. XRD spectra of PTO films on LAO and STO substrates grown from "stoichiometric" solutions consist only of $(00 l)$ and $(h 00)$ reflections (Fig. 4a) corresponding to c-axis and a-axis textured crystallites, respectively ( $c$ - and $a$ domains). The best crystallinity was obtained for films deposited at $650{ }^{\circ} \mathrm{C}$. PTO films on both STO and LAO substrates had very good in-plane orientation, as seen from pole figure for (102) reflection given in Fig. 7. Double peaks (split in $\chi$ angle) appear in pole figure of $a$-domains due to the domain twinning.

As it is known, $a$-domains and $c$-domains in epitaxial ferroelectric films are tilted by a small angle from the substrate plane normal due to the twinning phenomenon [4]. The $a$ domains and $c$-domains are bounded by the (101) twin plane, and this results in a tilt of [100] axis in $a$-domains, the tilt angle depending on the tetragonality of the cell (for $\mathrm{c} / \mathrm{a}=1.065$ the tilt angle is $3.7^{\circ}$ ) [4]. The tilt angle also depends on the domains volume fraction [34]. For films with a high fraction of $c$-domains, the $c$-domains tilt angle is very small [35]. Twinning is responsible for double rocking curves of $(00 l)$ and $(h 00)$ reflections and for the split in $\chi$ angle of peaks in pole figures (Fig. 7) of $a$-domains. Rocking curves of (001) reflection of PTO/LAO films deposited at different temperatures are given in Fig. 8. As mentioned about the surface morphology, twinning becomes a dominant factor when deposition is taken out at $650{ }^{\circ} \mathrm{C}$ or higher temperatures whereas the microstructure of layers deposited at lower temperatures is mainly determined by island growth. When layer is fully twinned (grown at temperatures $\geq 650$ ${ }^{\circ} \mathrm{C}$ ), the (001) rocking curve is double (Fig.8). The rocking curves of films deposited at lower temperatures are different. They become triple for film grown at $600 \mathrm{C}$ and lower temperatures: the peaks on both sides correspond to twinned zones and the central peak to nontwinned zones. This is in agreement with the fact that films grown at temperatures $\leq 600{ }^{\circ} \mathrm{C}$ are less or non-twinned and less textured than films obtained at higher temperatures. The twinning 
angles (tilt angles) for $a$ - and $c$-domains ( $\alpha_{a}$ and $\alpha_{c}$ respectively) in PTO films grown at various temperatures were estimated from rocking curves of (001) and (100) reflections and are given in Fig. 9. PTO films on STO have a highly dominant c-axis texture, so no split of rocking curve of (001) reflection in $c$-domains was observed. It is possible that the tilt angle of $c$-domains is too small to be detected.

PTO films grown at various temperatures on STO and LAO substrates consisted of both $a$ and $c$-domains (Fig. 10). However, the $c$-domains growth is dominant for all range of deposition temperatures because the a-parameter of PTO cell matches better the parameter of substrate cell. The quantity of a-axis (A, \%) textured crystallites in PTO films is clearly related to the deposition temperature and reaches the minimum in highly crystalline films grown at 650

C. As $a$-domains form only due to twinning, C.S. Ganpule et al. [33] proposed a relation between the twinning angles of $a$ - and $c$-domains and the $a$-domains fraction. This relation perfectly works for our PTO films on STO and LAO substrates: $\tan \alpha_{c} / \tan \alpha_{a}$ linearly depends on $\mathrm{A} /(1-\mathrm{A})$ (Fig. 11). The bigger the amount of $a$-domains, the bigger the tilt angle of $c$-domains and the smaller the twinning angle of $a$-domains.

\section{Conclusions}

The influence of various deposition conditions (deposition temperature, partial oxygen pressure and solution composition) was examined for the growth of $\mathrm{PbTiO}_{3}$ (PTO) films on various substrates by pulsed liquid injection MOCVD.

The oxygen partial pressure influences the $\mathrm{Pb}$ loss during the film growth and post deposition thermal treatments. The maximum $\mathrm{Pb} /(\mathrm{Pb}+\mathrm{Ti})$ ratio in the film was obtained using $37.5 \% \mathrm{O}_{2}$ in the gas flow during the deposition. The $\mathrm{Pb}$ loss during the cooling from high growth temperature can be reduced using high $\mathrm{O}_{2}$ pressure $(0.4 \mathrm{~atm})$.

The evolution of film composition, microstucture and morphology with solution composition at different deposition temperatures was investigated. Higher deposition temperatures requires bigger amount of $\mathrm{Pb}$ precursor in solution for achieving of the right cationic proportion in the film. This may be related to higher $\mathrm{Pb}$ desorption at higher temperatures. The solution composition and growth temperature highly influence the film morphology and microstructure. Epitaxial films on perovskite substrates consist of dominant caxis and minor a-axis textured zones ( $c$-domains and $a$-domains). The surface morphology is mainly determined by island growth for films grown at temperatures $\leq 600{ }^{\circ} \mathrm{C}$ and by twinning phenomenon for films grown at temperatures $\geq 650{ }^{\circ} \mathrm{C}$. Fully twinned or partially twinned films 
can be obtained by varying deposition conditions. Twinning is observed in both $a$ - and $c$ domains and twinning (tilt) angles depend on $a$-domains fraction. The best crystallinity and the lowest $a$-domains fraction were obtained in epitaxial films grown at $650{ }^{\circ} \mathrm{C}$ on $\mathrm{LaAlO}_{3}(001)$ and $\mathrm{SrTiO}_{3}(001)$ substrates. 


\section{References}

[1] J.F. Scott, C.A. Araujo, "Ferroelectric memories", Science 246 (1989) 1400-1405.

[2] K. Ohtani, K. Okuyama, Y. Hamakawa, " $\mathrm{PbTiO}_{3}$ thin film ultrasonic micro-sensor fabricated on Si wafer”, Jpn. J. Appl. Phys. 23(Suppl. 23-1) (1984) 133-135.

[3] R. Takayama, Y. Tomita, K. Iijima, I. Ueda, "Pyroelectric linear array infrared sensors made of c-axis oriented La-modified $\mathrm{PbTiO}_{3}$ thin films”, J. Appl. Phys. 63 (1988) 58685872.

[4] M. de Keijser, D.M. de Leeuw, P.J. van Veldhoven, A.E.M. de Veirman, D.G. Neerinck, G.J.M. Dormans, "The structure of heteroepitaxial lead titanate layers grown by organometallic chemical vapour deposition”, Thin Solid Films 266 (1995) 157-167.

[5] Y.F. Chen, T. Yu, J.X. Chen, L. Shun, P. Li, N.B. Ming, "PbTiO ${ }_{3}$ films prepared by metalorganic chemical vapour deposition on $\mathrm{LaAlO}_{3}$ ”, Appl. Phys. Lett. 66(2) (1995) 148150.

[6] C. Schmidt, E.P. Burte, "MOCVD of ferroelectric thin films", Microelectron. Reliab. 39 (1999) 257-260.

[7] H. Funakubo, K. Nagashima, K. Shinozaki, N. Mizutami, "Comparison of deposition behavior of $\mathrm{Pb}(\mathrm{Zr}, \mathrm{Ti}) \mathrm{O}_{3}$ films and its end-member oxide films prepared by MOCVD", Thin Solid Films 368 (2000) 261-265.

[8] I.E. Korsakov, A.R. Kaul, L. Klippe, J. Korn, U. Krause, M. Pulver, G. Wahl, “Deposition of $\mathrm{PbTiO}_{3}$ thin films from thd-complexes by an aerosol source MOCVD method", Microelectron. Eng. 29 (1995) 205-208.

[9] Y.K. Kim, S.S. Kim, H. Shin, S. Baik: “Thickness effect of ferroelectric domain switching in epitaxial $\mathrm{PbTiO}_{3}$ thin films on $\mathrm{Pt}(001) / \mathrm{MgO}(001)$ ”, Appl. Phys. Lett. 84(25) (2004) 5085-5087.

[10] Y.M. Kang, S.C. Bae, J.K. Ku, S. Baik, "Preparation of epitaxial $\mathrm{PbTiO}_{3}$ thin films by pulsed laser deposition", Thin Solid Films 312 (1998) 40-45.

[11] K. Wasa, Y. Haneda, T. Sato, H. Adachi, K. Setsune, "Crystal growth of epitaxially grown $\mathrm{PbTiO}_{3}$ thin films on miscut $\mathrm{SrTiO}_{3}$ substrate", Vacuum 51(4) (1998) 591-594.

[12] C.Y. Pan, D.S. Tsai, L.S. Hong, "Abnormal growth of lead titanate thin film in chemical vapour deposition of $\mathrm{Pb}\left(\mathrm{C}_{2} \mathrm{H}_{5}\right)_{4} / \mathrm{Ti}\left(\mathrm{O}^{\mathrm{i}} \mathrm{Pr}\right)_{4} / \mathrm{O}_{2}$ ”, Mat. Chem. Phys. 70 (2001) 223-230.

[13] L.S. Hong, C.C. Wei, "Effect of oxygen pressure upon composition variation during chemical vapour deposition growth of lead titanate films from tetraethyl lead and titanium tetraisopropoxide”, Mat. Lett. 46 (2000) 149-153. 
[14] C. Byon, J.W. Jang, B.W. Lee, "Corrrelation between domain structure and ferroelectricity in $\mathrm{PbTiO}_{3}$ thin films", Mat. Lett. 34 (1998) 308-311.

[15] G.J.M. Dormans, P.J. van Veldhoven, M. de Kreiser, "Composition-controlled growth of $\mathrm{PbTiO}_{3}$ on $\mathrm{SrTiO}_{3}$ by organometallic chemical vapour deposition”, J. Cryst. Growth 123 (1992) 537-544.

[16] M.U. Ramana Murty, S.K. Streiffer, G.B. Stephenson, J.A. Eastman, G.R. Bai, A. Munkholm, O. Auciello, C. Thompson, "In situ x-ray scattering study of $\mathrm{PbTiO}_{3}$ chemical vapour deposition", Appl. Phys. Lett. 80(10) (2002) 1809-1811.

[17] T.W. Kim, S.S. Youn, "Microstructural, electrical and transmittance properties of $\mathrm{PbTiO}_{3}$ films grown on p-InP (100) substrates at low temperature", J. Phys. Chem. Solids 60 (1999) 935-942.

[18] S.W. Chung, S.O. Chung, K. No, W.J. Lee, "Crystalline structures of the $\mathrm{PbTiO}_{3}$ films prepared using the ECR PECVD method”, Thin Solid Films 295 (1997) 299-304.

[19] K. Nishida, G. Matuoka, M. Osada, M. Kakihana, T. Katoda, "Effect of the substrate on properties of PTO thin film”, Appl. Surf. Sci. 216 (2003) 318-322.

[20] Y. Gao, G. Bai, L. Merkle, H.L.M. Chang, D.J. Lam, "Effects of substrate orientation and cooling rate in microstructure of $\mathrm{PbTiO}_{3}$ thin films grown by metal-organic chemical vapour deposition", Thin Solid Films 235 (1993) 86-95.

[21] K. Tokita, F. Okada, "Fabrication of $\mathrm{PbTiO}_{3}$ thin films by laser metalorganic chemical vapour deposition”, Nuc. Ins. Met. Phys. Res. B 121 (1997) 408-411.

[22] B. Malic, M. Kosec, K. Smolej, S. Stauber, "Effect of Precursor type on the microstructure of $\mathrm{PbTiO}_{3}$ thin films", J. Eur. Ceram. Soc. 19 (1999) 1345-1348.

[23] A. Erbil, W. Braun, B.S. Kwak, B.J. Wilhens, L.A. Boatner, J.P. Budai, "Oxide ferroelectric materials grown by metalorganic chemical vapour deposition", J. Cryst. Growth 124 (1992) 684-689.

[24] M. Tong, G. Dai, D. Gao, "Plasma-enhanced chemical vapour deposition of $\mathrm{PbTiO}_{3}$ ", Mat. Lett. 46 (2000) 60-64.

[25] J.A. Rebane, O.Y. Gorbenko, S.G. Suslov, N.U. Yakovlev, I.E. Korsakov, V.A. Amelichev, Y.D. Tretyakov, "CVD synthesis and SNMS characterization of thin films of $\mathrm{ABO}_{3}$ perovskite-type materials $\left(\mathrm{PbTiO}_{3}, \mathrm{La}(\mathrm{Sr}) \mathrm{CoO}_{3}, \mathrm{La}(\mathrm{Sr}) \mathrm{MnO}_{3}, \mathrm{LaNiO}_{3}\right)$ ", Thin Solid Films 302 (1997) 140-146.

[26] P. Lu, H. Li, S. Sun, B. Tuttle, "Novel single-solid-source metalorganic chemical vapour processing of PT and PZT thin films”, J. Cryst. Growth 171 (1997) 453-457. 
[27] J.P. Sénateur, F. Weiss, O. Thomas, R. Madar, A. Abrutis, "Procédé et dispositif d'introduction de précurseurs dans une enceinte de dépôt chimique en phase vapeur", Patent FR2707671 (1993), PCT FR94/00858 (1994), US5945162 (1999), Eu EP730671 (1996).

[28] J.P. Sénateur, A. Abrutis, F. Felten, F. Weiss, O. Thomas, R. Madar, in "Advances in Inorganic Films and Coatings”, P. Vincenzin, Ed. Florence, Italy: Techna srl, 1995.

[29] J.P. Sénateur, C. Dubourdieu, V. Galindo, F. Weiss, A. Abrutis, in "Innovative processing of films and nanocrystalline powders", K.-L. Choy, Ed. London: Imperial College Press, 2002.

[30] S.Y. Chen, I.W. Chen, "Texture development, microstructure evolution, and crystallization of chemically derived PZT thin films”, J. Am. Ceram. Soc. 81 (1998) 97-105.

[31] S.H. Kim, J.G. Hong, S.K. Streiffer, A.I. Kingon, "The effect of $\mathrm{RuO}_{2} / \mathrm{Pt}$ hybrid bottom electrode structure on the leakage and fatigue properties of chemical solution derived $\mathrm{Pb}\left(\mathrm{Zr}_{\mathrm{x}} \mathrm{Ti}_{1-\mathrm{x}}\right) \mathrm{O}_{3}$ thin films", J. Mat. Res. 14 (1999) 1018-1025.

[32] Y. Yao, S.G. Lu, H. Chen, K.H. Wong, "Effects of postdeposition annealing on the dielectric properties of antiferroelectric lanthanum-doped lead zirconate stannate thin films derived from pulsed laser deposition", J. Appl. Phys. 96(10) (2004) 5830-5835.

[33] C.S. Ganpule, V. Nagarajan, B.K. Hill, A.L. Roytburd, E.D. Williams, S.P. Alpay, A. Roelofs, R. Waser, L.M. Eng, "Imaging three dimensional polarization in epitaxial thin films grown by pulsed laser deposition”, J. Appl. Phys. 91 (2002) 1477-1481.

[34] Y.M. Kang, J.K. Ku, S. Baik, “Crystallographic characterization of tetragonal (Pb,La) $\mathrm{TiO}_{3}$ epitaxial thin films grown by pulsed laser deposition”, J. Appl. Phys. 78 (1995) 26012606.

[35] C.M. Foster, Z. Li, M. Buchet, D. Miller, P.M. Baldo, L.E. Rehn, G.R. Bai, D. Guo, H. You, K.L. Merkle, "Substrate effects on the structure of epitaxial $\mathrm{PbTiO}_{3}$ thin films prepared on $\mathrm{MgO}, \mathrm{LaAlO}_{3}$, and $\mathrm{SrTiO}_{3}$ by metalorganic chemical vapour deposition", J. Appl. Phys. 78 (1995) 2607-2622. 


\section{Figure captions}

Fig. 1: Pb content in PTO/LAO films: (a) influence of oxygen percentage in gas flow during deposition, (b) influence of annealing temperature and oxygen partial pressure.

Fig. 2: Composition of PTO/LAO films in relation with solution composition.

Fig. 3: AFM images $\left(2 \times 2 \mu \mathrm{m}^{2}\right)$ of various compositions PTO/LAO and PTO/STO films deposited at different temperatures. The average roughness $\mathrm{Ra}$ and $\mathrm{Pb} /(\mathrm{Pb}+\mathrm{Ti})$ ratio $(\%$ in film $)$ are given on photos.

Fig. 4: XRD patterns of (a) stoichiometric and (b) Pb deficient PTO/LAO films grown at $650^{\circ} \mathrm{C}$.

Fig. 5: Identification of two zones with different morphology in $\mathrm{Pb}$ deficient $\mathrm{PTO} / \mathrm{LAO}$ film:

(a) Raman spectra of two zones, (b) image of optic microscope and (c) AFM image.

Fig. 6: Average roughness (Ra) of PTO films versus deposition temperature $(\mathrm{Pb} / \mathrm{Ti} \sim 1)$.

Fig. 7: Pole figure of (102) reflection of PTO/LAO film grown at $650{ }^{\circ} \mathrm{C}$.

Fig. 8: Evolution of (001) rocking curves in $c$-domains of PTO/LAO films with deposition temperature.

Fig. 9: Evolution of twinning angles in $a$ - and $c$-domains with deposition temperature.

Fig. 10: Evolution of $a$-domains percentage (A, \%) in films with deposition temperature.

Fig. 11: Relation between twinning angle and $a$-domains fraction $(\mathrm{A} /(1-\mathrm{A}))$ in $\mathrm{PTO}$ films. 
Tables

Table 1: Deposition conditions for $\mathrm{PbTiO}_{3}$ layers by pulsed liquid injection MOCVD

Substrates

Substrate temperature, ${ }^{\circ} \mathrm{C}$

Evaporation temperature, ${ }^{\circ} \mathrm{C}$

Transport gas

Total gas flow rate, $1 / \mathrm{h}$

Oxygen fraction, $\%$

Total pressure, Torr

Precursors

Solvent

Solution concentration (total), $\mathrm{mol} / \mathrm{l}$

Injection frequency, $\mathrm{Hz}$

Thickness, nm
$\mathrm{SrTiO}_{3}(100), \mathrm{LaAlO}_{3}(001-$ in a pseudo-cubic setting), sapphire (R-plane), Si (001)

$$
550-750
$$

280

$\mathrm{Ar}+\mathrm{O}_{2}$

60

7-50

5

$\mathrm{Pb}$ (thd $)_{2}$, Ti(thd $)_{2}\left(\mathrm{O}^{\mathrm{i}} \mathrm{Pr}\right)_{2}$

Toluene

0.04

2

100-300 

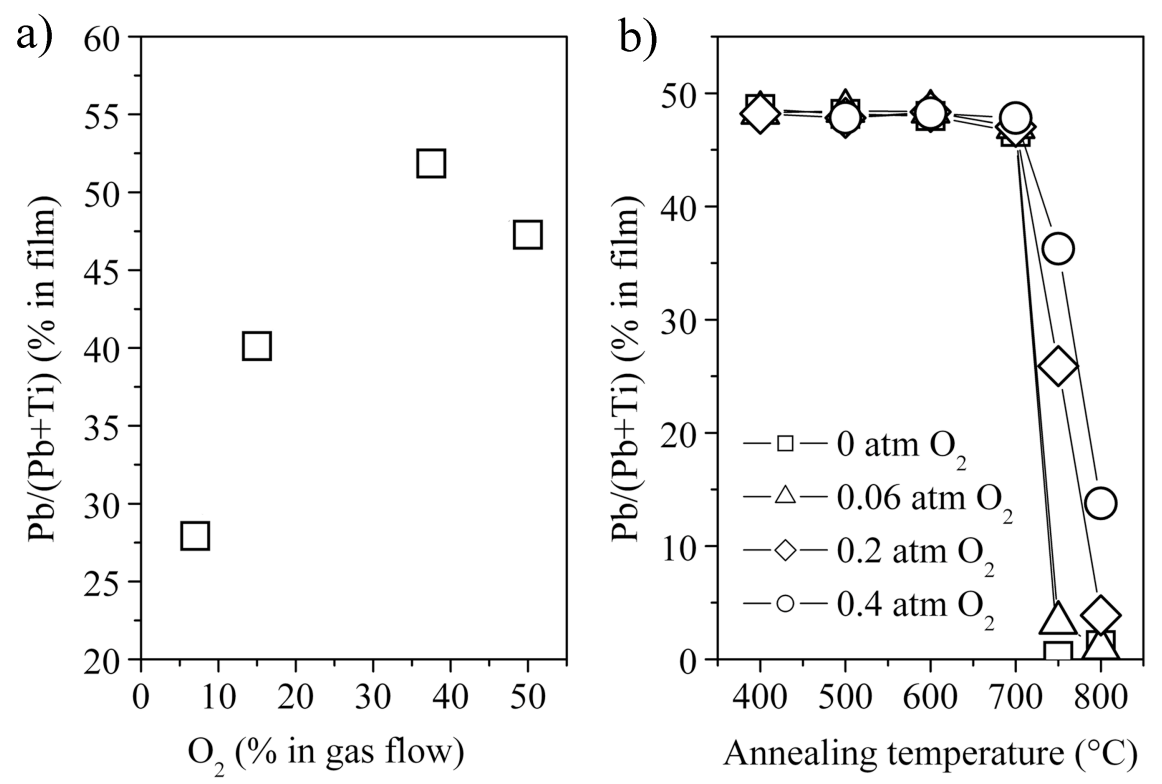

Fig. 1

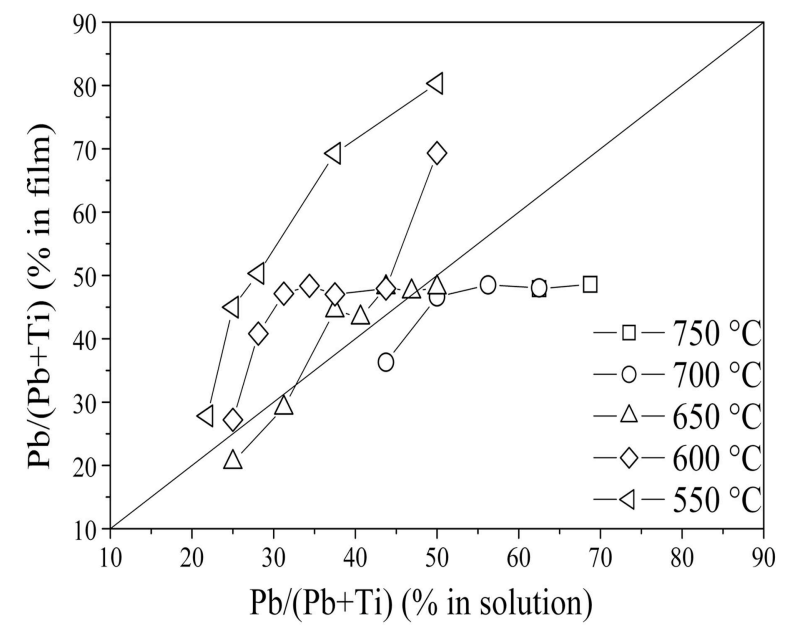

Fig. 2 


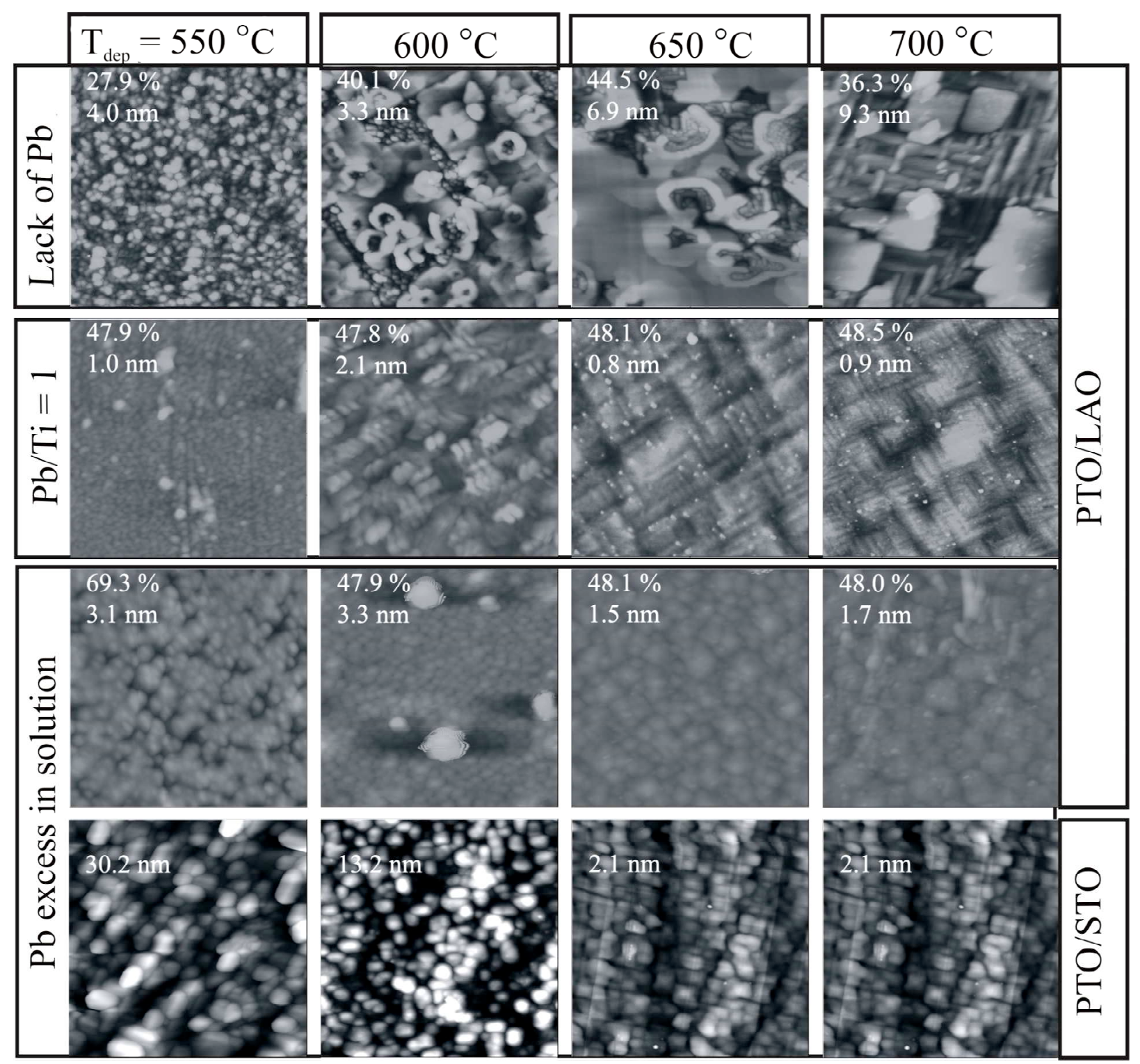

Fig. 3 

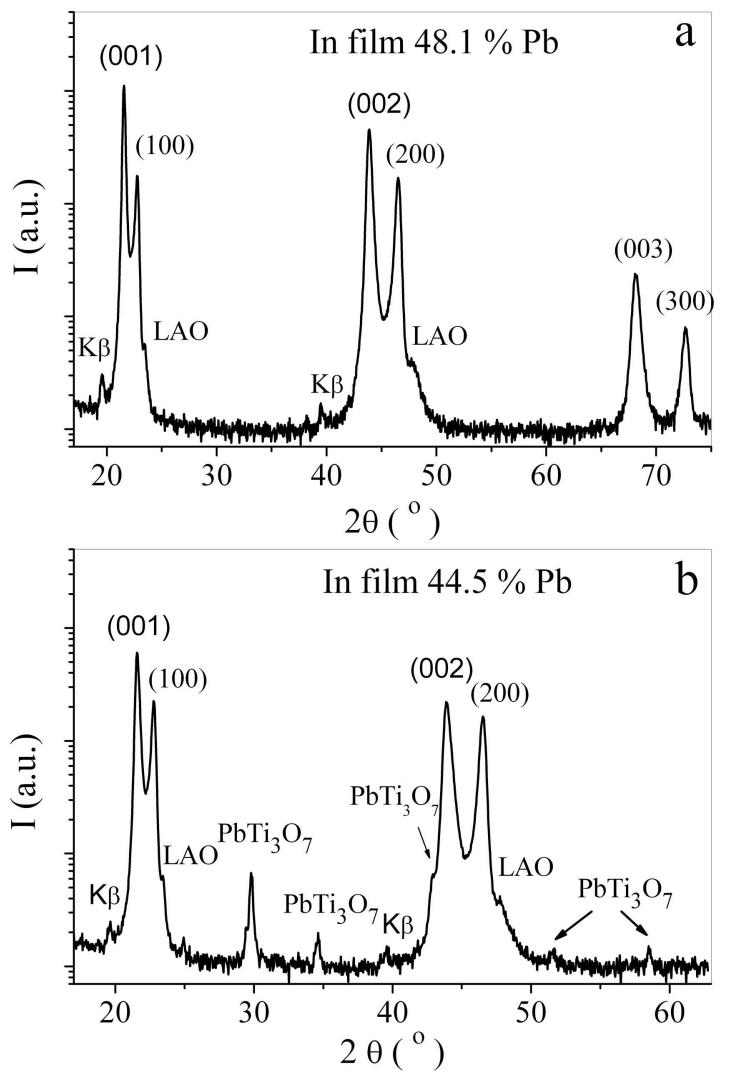

Fig. 4

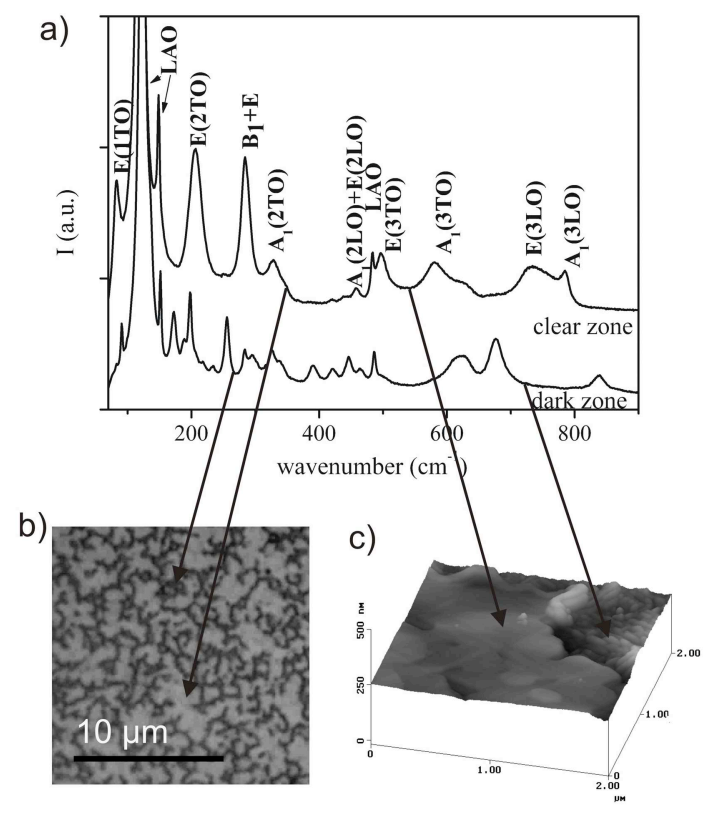

Fig. 5 


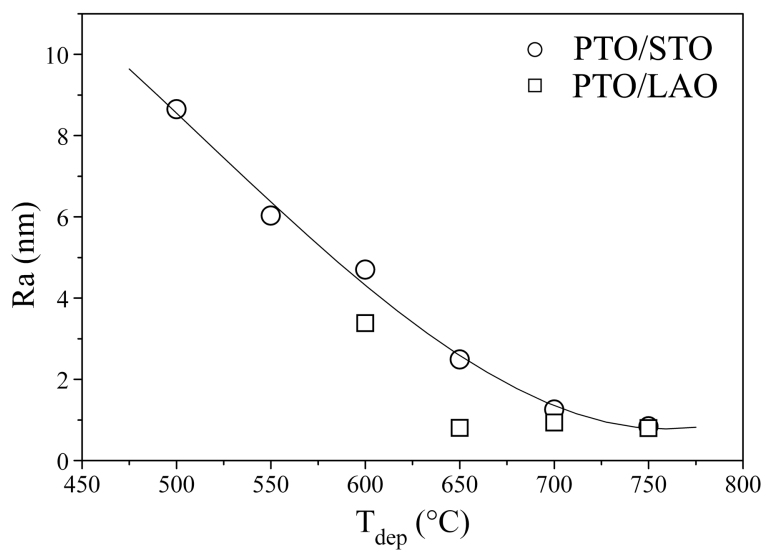

Fig. 6

a)

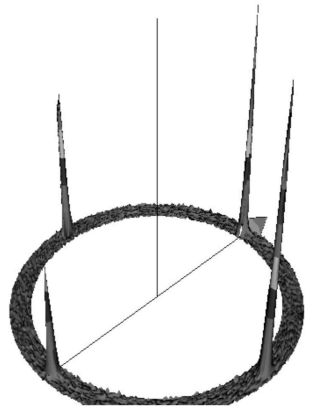

c-domains

$25<\chi>30$ b)

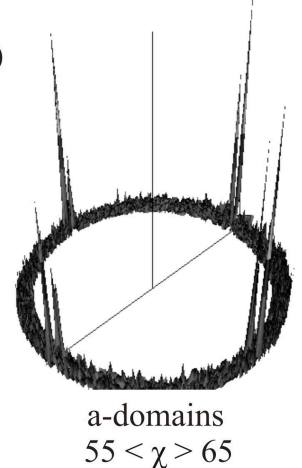

Fig. 7

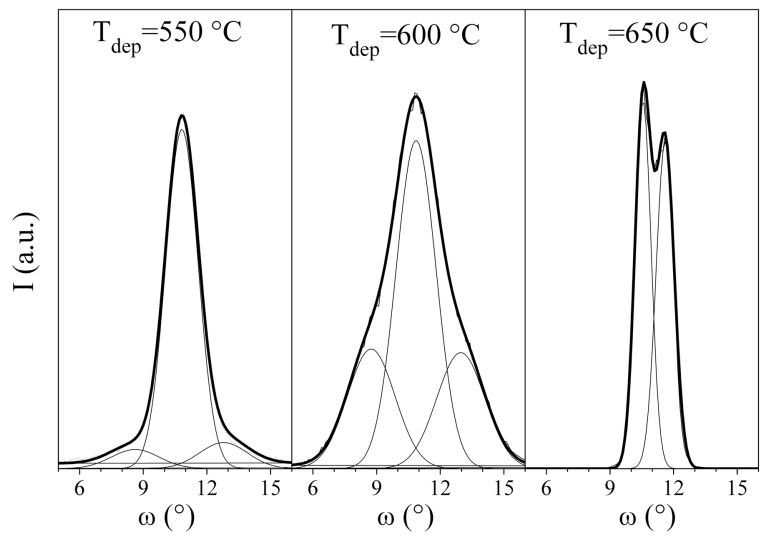

Fig. 8 


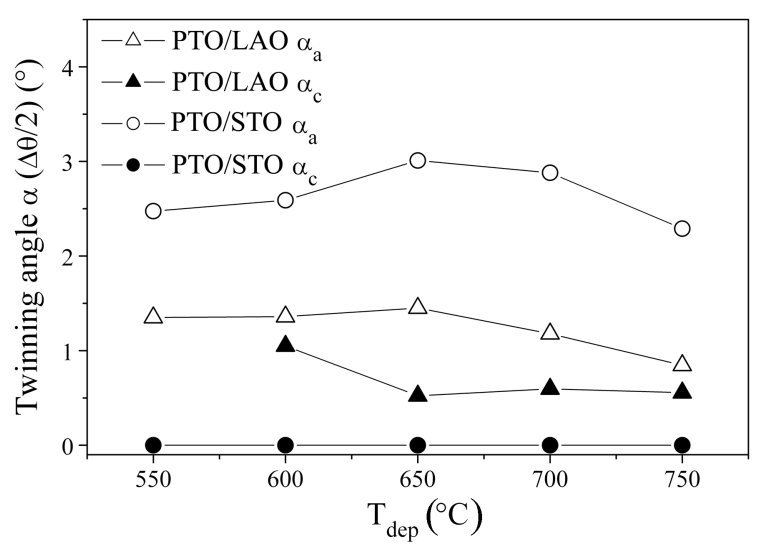

Fig. 9

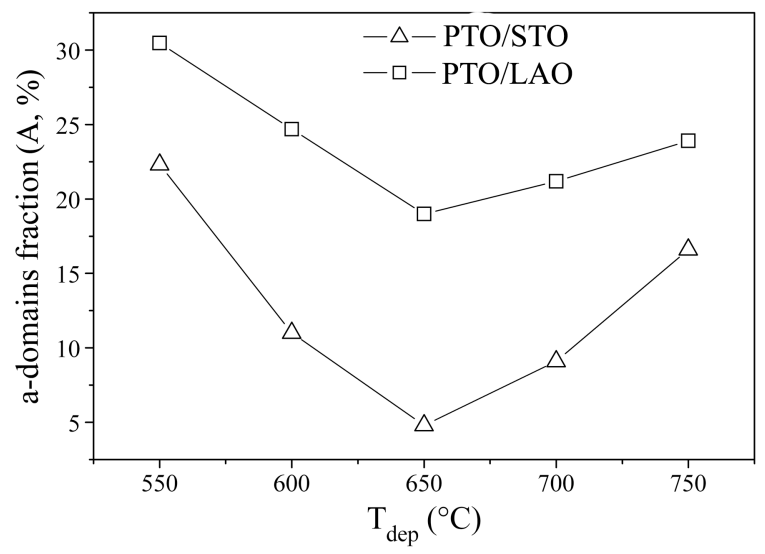

Fig. 10

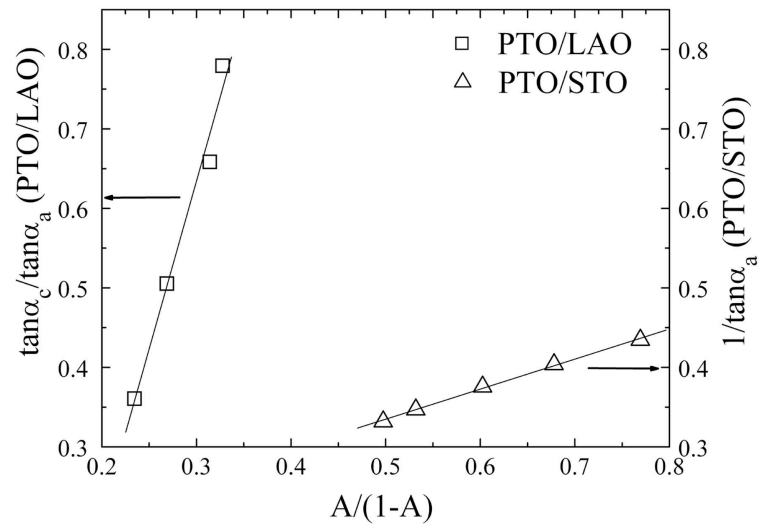

Fig. 11 